\title{
Negotiations in Public-Policy Making: Exogenous Barriers to Successful Dispute Resolution
}

\author{
KATHARINA HOLZINGER Politcal Science, Max Planck Project \\ Group on Common Goods
}

\begin{abstract}
The number of public policy conflicts has increased sharply in most western democracies, especially in the fields of planning, regional development, and environmental policy. Attempts have been made to find a way out through new forms of negotiation-based conflict resolution. Alternative Dispute Resolution raises high expectations as to its potential for reaching consensual solutions, to be achieved through extended participation, transparency, and procedural justice. However, success or failure of negotiations do not depend only on the procedure, but also on factors exogenous to it. The first section addresses the question: which exogenous factors affect the opportunities for an agreement in public policy negotiations and how do they exert their influence? Spatial representation of bargaining is used as an analytical framework. The second section shows how outside options, exogenous restrictions, and political directives for the negotiators affected the negotiation space and the final outcome in a case of environmental mediation in Germany.
\end{abstract}

\section{Introduction}

During the past 25 years, there has been an observable increase in the number and severity of political conflicts surrounding development projects, siting-decisions, new technology, risk, environmental impacts, and the distribution of the associated burdens and benefits. At the level of basic decisions concerning alternative uses of the environment or the introduction of new technologies, the public debate has been characterized by growing fundamentalism and, increasingly, even by violent confrontation. Planning and development have frequently become the targets of lengthy and tedious conflict. 
In several Western democracies, attempts have been made to find a way out of these problems by trying out new forms of conflict resolution based upon negotiation and participatory procedures such as policy dialogue, consensus conferences, participatory technology assessment, mediation, or facilitation. While Alternative Dispute Resolution (ADR) procedures seem to have been very successful in the USA and in Canada (Bingham 1986; Goldberg, Sander, and Rogers 1992), so far they have not been widely used in Europe (Weidner 1998). They are tied, however, to elevated expectations concerning increased participation, procedural justice, and greater transparency. A rational, cooperative approach is expected to result in quicker, fairer, less costly, and more consensual dissolution of conflict. In this way, policymakers and practitioners hope that decisions taken by the state will find greater acceptance among the public, that social integration will improve, and that the efficiency and flexibility of state action will increase significantly. ${ }^{1}$

In particular, it is expected and desired that the new procedures should contribute to de-fundamentalising the positions of conflicting parties. To this end, some specific mechanisms will have to be employed that work effectively within the procedures. According to van den Daele and Döbert $(1995,12)$, the very fact that the process of dispute resolution no longer means debate in an open public forum but rather a discourse between conflicting parties at which they are physically present, has a rationalizing effect; namely, participants are under pressure to provide arguments, and they are under the informed observation and control of other participants. Unlike the mass media or public forum debate, participants in organized discourse are forced, on the one hand, to consider counterarguments and, on the other, to avoid selectivity in their own choice of arguments.

This argument is based on Habermas' (1984) discourse theory, which distinguishes strategic and communicative action. The latter requires that speakers mean what they say, that there are no power asymmetries between speakers which are not normatively justified, and that speakers do not try to manipulate others. A Habermasian discourse (1993) is an ideal speech situation concerned with the justification of collective norms. A discourse must be public, everyone concerned shall take part, and every participant shall have equal rights. The participants are supposed to engage in communicative action only, they are required to act impartially and to be ready to change their preferences. It is the better argument that shall count in a discourse, not individual interest. The principle of universality secures that the participants reach a consensus: For each norm to be valid it is required that the consequences which would arise from common compliance with the norm for each 
individual will be accepted by all individuals concerned. Thus, discourse theory provides a normative theory of rational argumentation and a justification of collective decisions upon norms.

The so-called Harvard concept for successful negotiation also has as its main aim putting the whole process on a more rational basis. The core underlying both procedural rationality concepts is basing one's position on arguments. In contrast to Habermas, however, the individual parties to a negotiation are not required to sacrifice their personal interest and to act impartially. Proper negotiation has four basic rules (Fisher, Ury, and Patton 1997): First, emotions should be separated from the factual basis of the problem; second, the parties to the conflict should concentrate on their 'interests' instead of clinging to their 'positions'; third, as many alternative solutions as possible should be developed and considered; and finally, the various options for solutions should be subject to neutral criteria of evaluation. Improved communication between the conflicting parties, resulting from the generation of more relevant information and the systematic, rational analysis of arguments, should create a less hostile environment, in which the parties are willing to make concessions and pursue compromise to the benefit of everyone.

According to these theories, making positions more flexible and reaching consensus will be the result of internal process factors. The procedure itself, however, will meet with limitations. As has been shown by Arrow et al. (1995), barriers to successful negotiation are manifold. They can be found at the level of the individual parties, the negotiating collective, the strategic constellation, or the social and institutional environment the conflict is embedded in; they can result from psychological or social factors, from information states, or from utility calculations. Only some factors can be influenced through the procedure, mostly those that are closely related to the individuals and their interactions. Emotional factors may perhaps be overcome in and by the procedure, information asymmetries diminished, probability assessments corrected, and so on. However, there are many factors that are beyond the control of the participants in the negotiation, for example legal provisions which allocate asymmetric power to the parties or forbid certain solutions to the conflict. Those factors influence the negotiation situation, its course and its outcome, insofar as they co-determine the bargaining space and the bargaining power of the parties. Exogenous facts enter the negotiation by including or excluding possible solutions, and especially by affecting the utility calculus of the negotiating parties.

The actors' willingness to compromise, for instance, is not determined solely at the procedural level. The course negotiations will take and the final results of bargaining are not matters determined just by 
behaviour 'at the negotiating table' but also and perhaps even more so by what goes on 'away from the negotiating table' (Lax and Sebenius 1985). ADR procedures can be generally understood to be procedures in which the disputing parties voluntarily come together in an attempt to find a better solution or achieve a better result than they would have, had they done without such a procedure in the first place. This means, however, that whatever individual parties believe they could have achieved without the procedure becomes of central importance.

Crucial for an actor's decision whether to participate in the first place, whether to stay or whether to drop out of such a procedure will be his or her expectations as to the 'best alternative to a negotiated agreement' (BATNA). ${ }^{2}$ Prescriptive negotiation theory directs the negotiation partners to examine their own BATNA and that of their opponent. To actually do so, however, remains the task of the individual parties. The ADR literature concentrates for the most part on what goes on inside the procedure itself. External influencing factors are usually not given systematic attention. Lax and Sebenius (1985) constitute a notable exception: They analyse BATNA and its importance for bargaining power, and show how BATNA, and consequently the room for negotiation, can be influenced by the negotiators. BATNA can, however, be influenced by the conflicting parties themselves only to a limited degree; it is determined in part by factors completely independent of the negotiating parties, such as market forces or legal regulations.

In section 2, I begin by presenting the BATNA concept, using a simple technique of spatial representation of bargaining. It does not use any specific bargaining model, such as the co-operative Nash solution (Nash 1950) or the non-cooperative Rubinstein model (Rubenstein 1982) but applies the spatial representation to a bargaining situation, as has been done by others before (cf. Scharpf 1997: 116-150, Raiffa 1982). The focus is on the question, how the bargaining space is influenced by factors exogenous to the negotiation. What underlies BATNA in real world negotiations, that is, how is it constituted, and how are negotiations influenced by events and strategies 'away from the negotiation table'? I first examine what is specific in public policy negotiation compared to the individual bargaining captured in economic models. Next I examine three possible forms exogenous influences can take: outside options, restrictions on possible solutions, and political directives. In section 3, a case study illustrates how the actors' BATNA considerations, external restrictions, and political directives have affected a concrete public policy negotiation procedure. The case is the mediation procedure initiated over the issue of a waste management plan for the county of Neuss in the German Federal State of North Rhine-Westphalia. The spatial framework is used to produce 
a rational reconstruction of the case. The case is typical of an implementation conflict; similar conflicts take place all over Western democracies and in many different policy fields. The case is also typical of collective bargaining of governmental and private actors. The theoretical considerations and the three types of exogenous influences presented in the first part are generalizations from the case study. As this paper presents a case study and analyses it by a rational choice framework, it hopefully qualifies as an analytic narrative as proposed by Bates et al. (1998).

\section{Exogenous Influences in Collective Negotiations}

\section{I The Bargaining Framework}

The point of departure for ADR as for any bargaining model is the idea that the primary motive for seeking a negotiated solution to a problem is that the parties anticipate a better outcome from negotiation than they could expect without it; that is, they expect to gain from cooperation. It is clear, therefore, that parties would not accept a bargaining outcome that would be worse for them than their own 'best alternative to a negotiated agreement'. The outside options ${ }^{3}$ influence not only the conflicting parties' decision to participate or to drop out, but also their willingness at a particular stage in negotiations to modify or withdraw some of their initial demands, to make concessions, agree to a compromise or, in general, demonstrate flexibility.

Using the spatial representation of a bargaining game, the BATNA concept can be demonstrated more precisely. Two parties are negotiating over a set of possible outcomes. Figure 1 depicts the valuations of both players, $u_{\mathrm{i}}$, of all possible alternatives in the utility space, $P$. The utility frontier, $N$, restricts the room for negotiation to those options that are feasible. For any given utility of one player, $N$ indicates the maximum utility that is achievable for the other player. The intersections between the curve and the axes show, accordingly, the optimal outcomes for each player on his respective axis. Point $d$ is the threat point; it shows what the player's utilities, $d_{1}$ and $d_{2}$, would be if negotiations break down and the players take recourse to their outside options. Neither player would be prepared to accept an outcome whose utility was less than $d_{i}$. Conceptually, then, the threat point is just BATNA. It restricts the room for negotiation by reducing the feasible alternatives to only those that would truly be acceptable to both parties. Therefore, the players negotiate only over those alternatives that lie in the area circumscribed by $d, a$, and $b$. It is not necessary for us to concern ourselves with the actual solution to the problem; what is important here 
Figure 1: Basic Bargaining Game

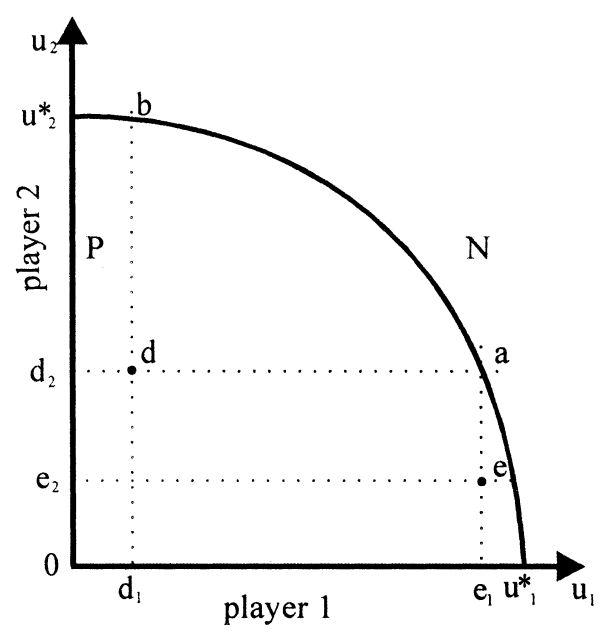

is that the parameters are defined by $N$ and $d$, and these are partly determined by factors external to the negotiation process.

The outside options are a significant determinant of a party's bargaining power (Fisher, Ury, and Patton 1997, 150; Lax and Sebenius $1985,171 \mathrm{ff}$.). The more attractive the outside options, the easier it is to forego further negotiation and therefore the greater the bargaining power. The negotiation partner whose optimal bargaining outcome and best alternative are closest together has the greatest bargaining power. This is shown by the second threat point, $e$, in figure 1 . The utility for player 1 at $e$ is $e_{1}$, a value only slightly below his or her maximum utility of $u_{1}^{*}$; whereas for player 2 at $e$, in contrast, the gap from $e_{2}$ to $u_{2}{ }_{2}$ is very large. Player 1 , therefore, is in a substantially better position to push his or her aims through than player 2 .

\section{2 Collective Negotiations in Public-Policy-Making}

Alternative dispute resolution procedures in public policy conflicts are negotiations between political organizations. Negotiations of this type are different from negotiations between individual persons in two ways. First, in such procedures, the parties negotiate not only on their own behalf as individuals, they also negotiate as representatives on behalf of an organization. The room for negotiation is limited from the very beginning by the goals set by the respective organizations or constituencies; important decisions require regular consultation with and feed- 
back from the membership or the constituencies represented. Second, in such negotiations, the participating organizations can be seen as self-interested political agents. Political parties, business associations, administrative agencies, public authorities, or private companies, in addition to having concrete aims at the factual level of the conflict, also pursue political-strategic aims. Taking an example from the case study, a substantive goal, could be pushing through the construction of a waste incineration plant or, contrarily, preventing the construction of a waste incineration plant. Examples of political-strategic goals, on the other hand, might be getting re-elected for political parties and politicians, mobilizing public support for citizens' initiatives or grassroots organizations, increasing their sphere of influence or lobbying power for business associations, maximizing profits and maintaining or increasing their entrepreneurial freedom for private companies. The relative importance of substantive goals and strategic goals for any given organization will vary according to the type of organization in question. For a citizen's initiative, for instance, whose aim it is to prevent the construction in their immediate vicinity of a polluting industrial plant, the substantive goal is primary. For longer lived, politically centred organizations like the established political parties, or politically involved organizations like business associations, political-strategic goals could clearly dominate.

BATNA considerations must include substantive as well as the political-strategic goals. In addition to the advantages and disadvantages that result from a negotiated agreement or an outside option at the substantive level, participation in ADR procedures can incur specific costs or benefits that may make a significant difference at the politicalstrategic level. The costs and benefits of participation include, on the negative side, the time and resources it is necessary to invest in them and, on the positive side, for instance, acquisition of relevant information, the ability to mobilize support among constituents, and greater possibilities to establish useful contacts or to build up information exchange networks. Over and above these, the willingness or unwillingness of an organization to take part in consensus oriented dispute resolution procedures can mean a gain or a loss in that organization's credibility among its clientele or the general public. For each individual case, the costs and benefits of participating must be weighed against the political-strategic implications of the alternatives to negotiating. This relatively complex assessment will be carried out by the participants not only just before the outset of negotiations; it will also be revised continually throughout the procedure in order to determine whether or not continued participation is justified or whether dropping out might not make more sense. Throughout the procedure the occur- 
Figure 2: Exogenous Restrictions and Outside Options

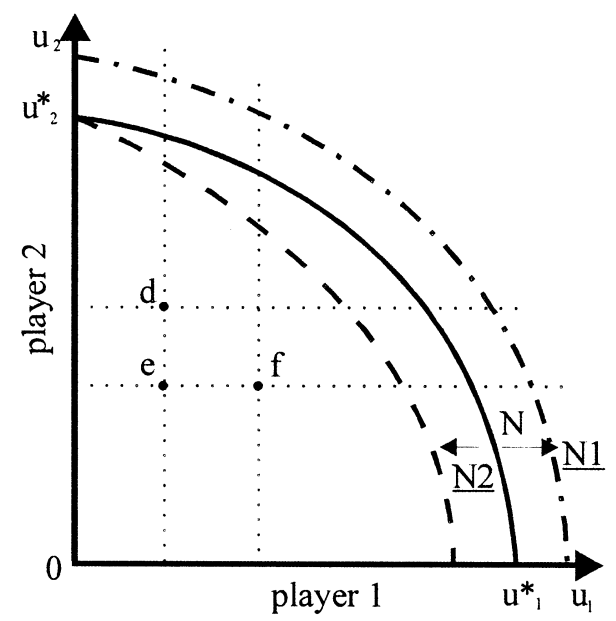

rence of internal and external events makes continual revision of initial assumptions and basic decisions absolutely necessary.

\section{3 Exogenous Factors in Public Policy Negotiations}

With respect to the main focus of this paper, the crucial events are the ones that occur away from the negotiating table. We can distinguish between three kinds of external events. First of all, changes can occur in the exogenous restrictions on possible solutions to a conflict. For instance, technical, economic, or legal restrictions that determine the set of possible alternative solutions from which disputants can select, can be eased, lifted, or abolished or, conversely, tightened or added to. Changes in the exogenous restrictions are illustrated by a shift in the utility frontier. For instance a shift from $N$ to $N_{l}$ as shown in figure 2 would result from expanded room for negotiation - a change to the advantage of both negotiating parties. In contrast, a shift from $N$ to $N_{2}$ restricts the payoff space to the disadvantage of player 1 .

Second, changes can occur in the outside options of some or all of the negotiation partners. For instance, shifting the threat point from $d$ to $e$ gives player 1 the advantage: player 1 now has more room for negotiation, that is, his or her set of possible alternatives has increased. At the same time, player 2's outside options are worse and, accordingly, his or her negotiating position is weakened. Shifting the threat point from $d$ to $f$ implies a worsening of the outside options for player 2 and, 
at the same time, a betterment in player 1's BATNA. All in all, player l's bargaining position is clearly stronger.

The outside options for the participants in public policy dispute resolution procedures or policy dialogues are essentially determined by the law, the economic system, and the political system. For example, the following alternative courses of action or outside options are conceivable: resolving the issue by state-level or local-level parliamentary decision, or through litigation; exercising the right of participation in administrative decision making procedures; lobbying and mobilizing public support; exercising illegal forms of protest. In individual cases, circumstantial factors determine the availability and feasibility of the options. The political roles of the negotiation partners determine which alternatives for action are available and how strong or weak these options are. For example, in environmental policy conflicts, the negotiation partners include, as a rule, political parties, administrative agencies or local authorities, environmental associations, citizens' initiatives, private companies, and business associations. Some actors, for instance, the political parties in power, or the local authorities, will have policy-making or decision-making power; other actors, for instance, opposition parties, or citizen's initiatives, will have the right to raise formal objection or litigate, the right to participate formally, or they will have informal and indirect power of influence. ADR procedures represent a situation in which every partner is basically endowed with equal rights in the procedure, but not equal power. Although, balance of power within ADR procedures is frequently insisted upon, it is a demand that will remain unfulfilled as long as the negotiation partners do not have equal power outside the negotiations.

The third way in which negotiations can be influenced from outside is that a participant's room for negotiation may be restricted by the organization or constituency he or she represents. This is the case if one of the bargaining partners represents, for example, a regional subdivision of a larger association, authority or political party and is therefore bound by the main organization's directives. In an international context the same problem has been analysed under the label of 'twolevel games' (Putnam 1988). However, in the course of negotiations, such directives can themselves be altered exogenously or can come under serious pressure as a result of the process itself. In the bargaining framework such directives imply that no negotiated solution should be accepted by the representatives of an organization that does not yield a minimum, fixed level of utility for that organization. In figure 3 , a directive with a utility level fixed at $x$ is drawn for player 1 . If such a directive is effective it can be expected to lie somewhere between BATNA and the optimal outcome for player 1, that is, somewhere 
Figure 3: Directives from the Bargainers' Constituencies

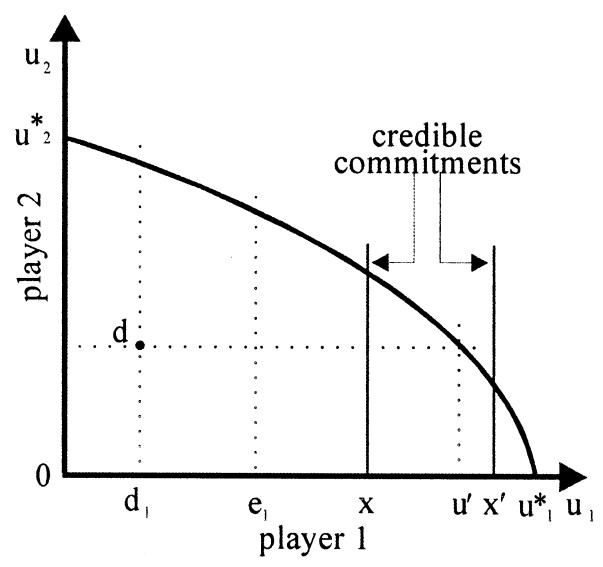

between $d_{1}$ and $u^{*}$. To commit oneself to $x$ might at first glance appear counterintuitive. If it is only possible to reach an agreement with player 2, for instance, when the solution lies between $d_{1}$ and $x$, then such a solution, $e_{1}$, would always seem to be preferable over the outside option, $d_{1}$.

Nevertheless, the strategic importance of the first credible commitment in the negotiation process should never be overlooked. As Schelling (1960, 22ff.) has shown, the side that always comes out ahead in a negotiated settlement is the side that is the first to make a credible and irreversible commitment to a solution, so long as this outcome is better to the opposing side than its best alternative. In this situation, the opposing side is left with only the choice to accept the proposed solution or to fall back on its worse outside option. A directive from a negotiating party's next highest authority, or constituency, for instance, can serve quite well as a credible commitment, especially if this directive reflects a widely accepted and well-known basic principle of the respective organization. Here, the commitment can secure a strategic advantage for a negotiating party, if the solution, like $x$, just reaches the level of acceptability of that party's opponents. However, if the solutions preset by organizational directives are less advantageous to the opponents than their own outside options - that is, if they, like $x^{\prime}$, lie between $u^{\prime}$ and $u^{*}$ - then negotiations break down. Sticking to a fixed position is then indeed irrational for player 1 because then he or she would have to fall back on his or her outside option.

In the following sections, I shall address the question of to what extent the mediation procedure over the waste management program 
in Neuss was influenced by exogenous factors. The course of the negotiations will not be described in detail, as the focus of analysis is on exogenous influences. Also, the total set of outside influences will not be dealt with here in its entirety; rather, I shall examine some characteristic examples: the disputants' BATNA calculations; exogenous restrictions which had very significant impacts on the mediation procedure and how a potential compromise was missed as a result of political directives.

\section{The Mediation Procedure on the Waste Management Programme in the} County of Neuss

\section{I The Subject of Dispute}

The mediation procedure in Neuss County, North-Rhine-Westphalia (NRW), was the second case of an environmental mediation in Germany, and the first one to be applied to a waste management programme. With nearly $5^{\text {Oo }}$ ooo inhabitants in its six cities and two rural communities, Neuss is the tenth largest county in Germany. County (Kreis) is the fourth administrative level in the German political system, after the Federal (Bund), State (Land), and District (Bezirk) levels. Counties have the right to take autonomous decisions in certain areas of competence. The political decisions are taken by the County Council, the local parliament. The County Administration is an executive body, which develops substantial programmes and implements policies.

In Germany state law ( $\xi_{5}$ a of the NRW waste law) assigns the responsibility for the disposal of domestic waste to the counties. Each county is required by law to develop and implement a concept for the disposal of domestic waste and to update this programme every five years. The draft for the 1991 domestic waste disposal concept in Neuss County ignited a serious public policy conflict that became the subject of the mediation. The concept planned for a new domestic waste incineration plant. The Neuss County Administration commissioned an expert report that proposed three possible locations to site the incineration plant. On the basis of this report, the county authorities favoured one particular site in the city Grevenbroich-Neurath.

However, long before the concept had been formally approved by the County Council, it met with solid and vigorous opposition from the local population and local environmental associations. The environmental groups doubted whether the waste management programme had exhausted every possibility of avoiding and recycling waste. Consequently, they saw no need for the construction of an incineration plant. Waste incineration was considered to be dangerous for the envir- 
onment by German environmentalists as a matter of principle, because of expected high levels of emissions into the air. Resistance came also from three citizen's action groups against waste incineration, the core of which consisted of residents living near the location favoured by local politicians and the County Administration.

On the Neuss County Council, the Social Democratic Party (SPD) and the Christian Democratic Party (CDU) governed jointly. Both parties were in favour of an incineration plant. However, in the following year, local elections were to be held. In the face of strong public opposition, every party that supported the construction of a waste incineration plant in Grevenbroich-Neurath, where the SPD held an absolute majority, had to reckon with a loss of votes. A 'yes' for the incineration plant could have meant the loss of the absolute majority for the SPD, especially in the face of a citizens' initiative plan to campaign for seats in the upcoming elections there. As the SPD did not have a majority on the County Council, it could not push a solution through against the GDU that was not based on incineration. On the other hand, the GDU and the Free Democratic Party (FDP) could not have pushed incineration through by themselves. Therefore, all Council factions were definitely willing to seek consensus on this issue. The parties and the Neuss County Administration publicly signalled their interest in resolving this conflict through a mediation procedure. They contacted the Science Centre Berlin for Social Research (WZB), which had a research unit devoted to ADR. The WZB proposed a mediator, and organised and accompanied the mediation procedure.

After an initial phase of preliminary talks held in the winter of 1991/ 92, a total of nine mediation sessions took place between 28 March 1992 and 27 August 1993. Altogether 27 organizations, including the Neuss County Administration, participated in this mediation: the local authorities of the eight county communities, the four political parties represented on the County Council at the time of the mediation, five citizens' initiatives, several county-level environmental associations, business associations, and two churches. The waste management programme including waste incineration was basically supported by the Neuss County Administration, most of the county community administrations, the SPD, the CDU, the FDP, and three business associations. In the following, I refer to this group collectively as the supporters. The Green Party (Greens), the environmental associations, the citizens' initatives, two local communities and two local churches opposed the waste management plan (the opponents). The hard core of the conflict was determined by two factors: acceptance or rejection of waste incineration as a technology per se; and acceptance or rejection of the proposed site, Grevenbroich-Neurath. 
After eight mediation sessions which were devoted to information gathering and the commissioning and discussion of reports, the Neuss County Administration surprisingly announced at the ninth meeting, that it was about to present a proposal to the County Council, in which Grevenbroich-Neurath as a definite site for the incineration plant had been selected and would be recommended. The environmental associations, the citizen's initiatives and the Greens declared that they could not support this proposal and that they would stick to their demand that residual domestic waste be treated bio-mechanically. The remaining participants either supported the Neuss County Administration's position or abstained from the vote. At this point in the mediation, the mediator saw no reason to continue with negotiations. The mediation ended without a consensus over the issue of waste treatment technology and over the issue of a site. Despite the remaining dissent, however, during the course of the mediation, consensus was achieved over a number of other factual questions including the introduction of more extensive waste avoidance and recycling measures (for details, Holzinger and Lackmann, 1995). ${ }^{4}$

In the following sections, insofar as other sources have not been named, the information on external factors presented here is based upon direct observation of the mediation procedure by the WZB research team and upon approximately $5^{\mathrm{O}}$ qualitative interviews conducted by the team, among them the author. The results of the interview survey are presented in Holzinger and Weidner (1997). Comprehensive accounts of the conflict and the mediation procedure itself are given in Fietkau and Weidner (1995), Fietkau et al. (1998), and in Napier (1998, 82-95). Internal and subjective factors have also been studied. Participants evaluations of the climate, the process and the result of the negotiations have been analysed on the basis of a quantitative survey (Pfingsten and Fietkau 1995, Holzinger 200o); a speech act analysis of the recorded negotiations shows that arguing and communicative action was present, but that interests of the parties proved stronger in the end (Holzinger 2001).

\subsection{The BATNA Calculus: Participant's Goals and Outside Options}

According to the BATNA concept, the utility for a participant in a negotiation must exceed the utility from dropping out and resorting to his or her outside option. In order to explain why the participants in ADR procedures decided to participate in the first place, it is necessary to examine both their substantive goals and their political-strategic goals. For the Neuss mediation procedure, this information was 
gathered during the mediator's preliminary talks with the parties to the conflict ${ }^{5}$ and during a round of interviews conducted shortly after the mediation procedure officially convened.

The decision to participate in the Neuss mediation presented no problem for most of the organizations represented. The Neuss County Administration was the initiator; all of the organizations on the supporting side of the administration's proposal were interested in taking part. During the preliminary talks, however, the opponents of the proposal were at first sceptical. The 'citizen's initiative against waste incineration" (BIMV) was the easiest of the citizen's initiative groups for the mediator to convince to take part and, once this had been achieved, the others followed suit. When the BIMV was asked about their alternative to mediation, they indicated that the Neuss County Administration could reckon with litigation initiated by members of their group. A lawsuit would in any case achieve for them postponement of the proposed project; in the worst case this would mean that the incineration plant would definitely be constructed, but at a later point in time; in the best case, its construction could be prevented altogether. The BUND's (the German affiliate of Friends of the Earth) reaction to the idea of mediation was initially basically positive. The BUND pointed out, however, that the costs in terms of time and resources to participate in a mediation were prohibitive for most of its members, who worked on an honorary basis. As its best alternative, the BUND feared that the waste management program would be implemented. They did not expect that their legal right to participate in the approved procedure (this is guaranteed under the German Nature Conservation $A c t$ ) would have any significant influence on the final outcome. The strongest reservations against a mediation were expressed by the Greens. They doubted the mediator's neutrality, they were unhappy with the exclusion of the press in the mediation and thus not having the option to 'appeal to the public', and they feared what they assumed was the informational and tactical superiority of their opponents. Over and above this, the Greens were faced with a dilemma of basic principle: If they took part in the mediation, they would lose their status as 'fundamental opposition' - a situation considered 'dangerous for green politics and policy'. As their alternative to mediation, they named political initiative in the County Council and litigation. Despite the various reservations, nearly all of those the mediator had asked, finally decided to take part in the mediation and were present throughout most of the sessions (Holzinger and Lackmann 1995).

During the interviews, the Greens and the environmental groups named as their substantive goals in the mediation to prevent the construction of a waste incineration plan and to improve the waste man- 
agement program by providing an expanded concept of waste avoidance and recycling. For most of the county community administrations, the SPD and one of the business associations, the goal was public acceptance of the waste management program and construction of the waste incineration plant. The GDU, some of the county community administrations and the churches pointed to goals with a 'collective good' character such as dissolution of the conflict, greater transparency in state decision making, better participation and reinforcement of democracy.

In terms of the core of the conflict, supporters and opponents alike referred only to their maximum achievable goals: acceptance of a waste incineration plant, on the supporters side and, on the opposing side, preventing the construction of a waste incineration plant and building a biomechanical waste treatment facility in its stead. The expectations of the disputants concerning the outcome of negotiations corresponded directly to their uncompromising stance. Of the 27 organizations represented in the mediation, only three believed that a consensual solution was possible: one church, one city administration, and one very politically inexperienced citizens' initiative group. All of the other parties either did not believe in consensus, or they were unsure. Among those who declined to venture a prognosis, were, notably, the Greens, the BUND, and some of the environmental groups. This could suggest that these organizations did harbour some hope that they might indeed be able to influence the final outcome by the mediation. Generally, in light of their substantive maximum goals and their almost unanimous expectations of irresolvable dissent over the incineration issue, participation in the mediation by most of the organizations who did in fact do so would seem scarcely reasonable. It can be assumed, therefore, that the BATNA calculations led to a negative result, if only the level of substantive goals would have been considered.

Figure 4 presents a simplified model of the above deliberations. On the horizontal axis the utility for the opponents of the plant is depicted; on the vertical axis, correspondingly, that for the supporters. ${ }^{6}$ The utility frontier is shown as a dotted line. The utility space is not continuously divisible; there are only very few possible outcomes to the conflict and these can be depicted as points. From the perspective of the conflicting parties prior to the mediation, there were only two possible outcomes to negotiation: (1) the construction of a waste incineration plant, or (2) the construction of a biomechanical waste treatment plant. Solution 1 would yield high utility for the supporters of the project but very little, in contrast, for the opponents; solution 2 would mean, conversely, high yield for the opponents, low yield for the supporters. BATNA results from the probable outcome without mediation: In the County Council, as a result of the SPD-CDU majority, the decision had 
Figure 4: BATNA considerations in the Neuss Mediation Procedure

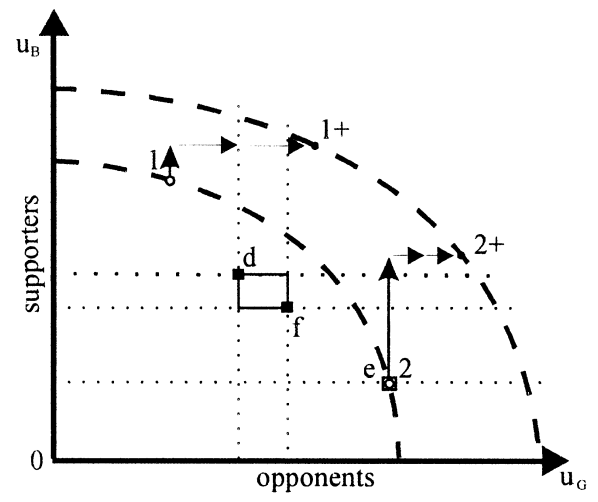

1 conventional incinerator, $\mathrm{p}=1$

2 biological waste treatment, $\mathrm{p}=1$

4 regaining of trust in politicians

$\rightarrow$ gains in time, in information and from networking

d incinerator at a later time

(after opposition and litigation), $\mathrm{p}=1$

e no incinerator (after litigation), $p=1$

$f$ incinerator at a later time (after litigation), $p=1 / 3$

been taken to build the incineration plant. After that, the opponents would have exercised their rights to participate in the approval procedure and to litigate, and used the possibilities at their disposal to mobilize the public. The result of this would have been delay but, ultimately, the construction of the waste incineration plant would have been assured, albeit at a later time than originally planned. Compared to the status quo at that time, this outcome would have meant a measurable loss to the Neuss County Administration in terms of additional costs in time and resources, and a loss in voter support for the majority parties in the County Council in the imminent elections; for the opponents of waste incineration, conversely, this outcome would have meant a clear gain in time. The utility in terms of this outside option, then, for both sides, is $d$ (figure 4 ). Both parties believed that they could achieve with certainty at least this outcome. But the opponents also saw a chance to be able to prevent the incinerator. This outcome is represented by $e$. If we assume that the probability assigned to this solution by the opponents was $1 / 3$, then the expected utility from the lottery containing $d$ and $e$ is $f$. In terms of the substantive goals, here, negotiation appears to be futile: all of the possible solutions lie outside the negotiation space.

This situation changes if we include the disputants' political-strategic goals obtained in our survey. The mediation offered the Neuss County Administration and the majority on the County Council the chance to demonstrate their willingness to accept public participation in controversial matters, and the opportunity to try to achieve greater acceptance for their waste management proposal. For the majority of participating organizations, a further motive for their interest was the 
opportunity to gain additional factual information about waste management in general and waste treatment technology in particular. On the opposing side, the most important strategic motives mentioned were that these organizations did not want to present themselves as incapable of submitting to consensus, that they wanted to establish additional contacts, and that they wanted to buy time. For the actors in the Neuss mediation, the costs and benefits of participation in terms of their political-strategic goals were a highly significant factor.

For the supporters, then, the value of possible alternative outcomes increases, if, as a result of mediation, the costs of conflict can be avoided and if these organizations can win additional political credibility, that is, if they can achieve a greater level of trust among the public. For the opponents, the expected utility from mediation lies in increased access to relevant information, better possibilities for networking, and gaining time. Thus, the utility for both solutions shifts on our graph (figure 4) to the right and upward; solutions $1+$ and $2+$ now fall within the negotiation space.

\subsection{Change of Legal and Technical Restrictions}

In the course of the Neuss mediation some of the external conditions changed. This meant that some new alternatives became possible, while others were excluded. One such change was the passing into law of a new federal regulation, the 'technical guidelines for domestic waste treatment' (TASi). The prevailing legal interpretation of this regulation is that the only residual waste treatment it allows, prior to waste being dumped, is incineration (Fietkau et al. 1998; Holzinger and Lackmann 1995). This meant that, compared to the situation at the outset of the mediation, the number of possible solutions had been reduced; and with that, the optimal solution for the opponents, biomechanical waste treatment, vanished from the spectrum of alternatives. During the mediation, expert testimony was heard on the probable impacts of the new legal situation for waste treatment and disposal practices. Most of the experts agreed that, in the face of the new regulation, thermal treatment of waste could no longer be dispensed with, while some others referred to 'special case' regulations (possible exceptions) and 'periods of transition'. The supporters of the Neuss waste management program and incineration technology clung to the interpretation of the TASi by the first group of experts; the opponents stressed what they saw as the legal leeway inherent in the TASi, that they believed the County of Neuss could surely exploit if only it had the political will to do so. This was not unreasonable to believe because the TASI was politically controversial and subject to renegotiation in the Bundesrat (the 
German Federal Council). This meant that there was a possibility that the incineration requirement provided for in the TASi could be eased.

Another change that affected room for negotiation in the Neuss mediation was a newly developed waste treatment technology based upon the principle of a high temperature carburettor: thermo-select treatment. Thermo-select treatment fulfilled the technical requirements of the TASi and, at the same time, it promised to be very cost effective and to reduce the level of emissions significantly over those expected from conventional incineration techniques. Nevertheless, there was much uncertainty about the performance and efficiency of this technology at the beginning of the Neuss mediation. At the end of the mediation, the majority of reports were, in fact, negative. This technology did, however, represent an additional possibility for resolution of the conflict, because it had the potential of being accepted by the local parties and the county government as well as by the environment groups. In our interviews, BIMV and BUND rated the thermoselect technology as worthy of consideration, but this view was not expressed openly during any of the mediation sessions.

Finally, the waste management program for the neighbouring County of Düren and this county's dispute with the next highest authority, the District Government, became a kind of reference model for the participants in the Neuss mediation. The 1991 Düren County waste management program included a biomechanical waste treatment plant. Throughout 1991 and 1992, the president of the District Government repeatedly warned the Düren County Administration that the construction of a bio-mechanical waste treatment facility in no way freed it from its legal obligation, as provided for in the TASi, to set up a waste incineration facility. The Düren County Administration, despite the warnings, would still not commit itself definitely to initiating a waste incineration project. The District Government, therefore, finally decided to initiate the planning and construction of the plant on its own, by decree. At approximately the same time, federal subsidies originally targeted for the Düren County biomechanical waste treatment model were withdrawn as a consequence of the TASi provisions. The parties to the Neuss mediation had been following the developments in Düren intensely. As a possible compromise solution to the Neuss conflict, some variation of the Düren model was in the back of everyone's mind: The revised waste management program for Neuss could include the planning and construction of a biomechanical waste treatment facility and, at the same time, announce the planned construction of a waste incineration plant for some future point in time. In this way, the 
Figure 5: Exogenous Restrictions in the Neuss Mediation Procedure

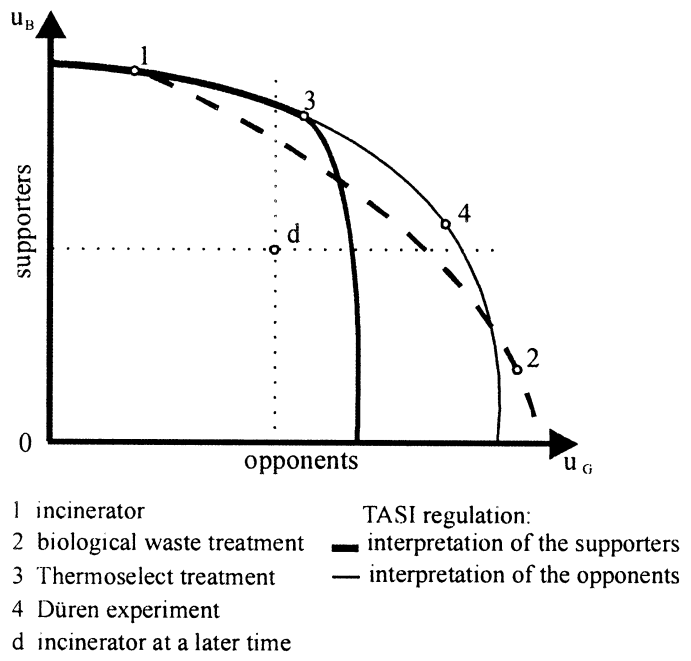

adversaries in the dispute could win time; they could wait for a final decision about the provisions in the TASi before actually proceeding with any plan.

The impact of the exogenous restrictions is depicted in figure 5 . The thermo-select procedure and the Düren model constitute two additional options that were not foreseeable at the outset of the Neuss mediation. Both solutions were - at least for a time - assessed by both sides in the conflict to be better than their own BATNA. During this phase both these options fall within the negotiation space. The thermoselect option, solution 3, more closely reflected the interests and possibilities open to the supporters of incineration technology. The Düren model, solution 4, conversely, reflected more closely the interests of the opponents. On the other hand, the fact that the TASi went into effect, clearly restricted the room for negotiation, because this regulation provided only for solutions based upon thermal processing of waste. It was clear on all sides, however, that the provisions of the TASi would be fulfilled just as well by a thermo-select facility as by a conventional waste incineration plant. The bold line represents this restriction on the room for negotiation; the thin line represents the interpretation of the TASi by the opponents of incineration, because they believed that a solution based upon the Düren model in terms of 'special case' provisions in the TASi was possible. 


\section{4 The Two-level Game: Political Directives Prevent a Compromise}

In the Neuss mediation, the conflicting parties did not come together. There were no explicitly stated, comprehensive proposals for compromise over the waste incineration issue. Up to July 1993, however, the Düren model stood as the 'virtual line of compromise' among the disputants in Neuss. From the interviews conducted in Neuss, a picture emerged suggesting that the BIMV, the BUND, the SPD, the CDU and the Neuss County Administration would have all been willing to accept a compromise like the Düren model; moreover, within the Neuss County Administration, it was also conjectured that the mediator favoured a solution of this type. ${ }^{7}$ Nevertheless, at the final session of the Neuss mediation, no offer of compromise of this sort was forthcoming by any of the participating organizations. The Neuss County Administration suggested that it would submit an application to register a blueprint for a thermal treatment plant as part of the regional development plan, but that it would not specify the exact technology to be used, nor would any final decision on investment be taken prior to 1995. This meant that the authorities were still open regarding thermo-select technology and that they were prepared to accept a delay in implementation; but obviously they did not want to go so far as to submit an application for a biomechanical waste treatment plant. The Greens and the environmental groups rejected the Neuss County Administration's proposal out of hand and, with that, the mediation ended in dissent.

Why was there no compromise in Neuss along the lines of the Düren model? For each of the groups involved in the Neuss conflict, the respective political directives can provide some clues to the answer to this question. The policy of the next highest waste management authority at District Government level, narrowed the parameters of negotiation within which Neuss County decision makers could manoeuvre. The District Government, like the State Government of North Rhine-Westphalia, preferred incineration as the accepted technology in residual waste treatment. They did not consider biomechanical waste treatment a feasible option - such a plant was not thought to be 'approvable' in view of the TASi regulation. For the County Administration, to plan it could have meant a court battle. Litigation would not necessarily have been imminent, since the higher waste management authorities can intervene only when continued waste disposal capacity is at risk. In Neuss, waste disposal capacity was still guaranteed for a relatively long time. Nevertheless, as the County Council representatives stressed repeatedly in the interviews, it would have been politically difficult for county level policymakers to take any decision that 
would have run counter to the wishes of the higher authorities. Moreover, the Neuss County Administration and the majority on the County Council (SPD and CDU), considered the situation in Düren relevant. Events there peaked at just the same time that the Neuss mediation reached its final phase. It became clear that Düren County's plans to reject a waste incineration plant would be thwarted by the District Government. Therefore, as the policymakers in Neuss perceived it, the feasible alternative solutions were reduced to options $I$ and 3 (figure 5).

Why, however, did the Greens and the BUND not respond to the proposal by the Neuss County Administration by appealing to the Düren model? Here again, political directives were relevant. The policy of the North Rhine-Westphalian state chapter of BUND and the state level Green Party was 'absolute rejection of waste incineration technology'. For the county level environmental associations and local level Greens in Neuss, therefore, it was not possible to give their consent to any form of waste incineration plant. In the case of the Greens, the policy line did not represent an additional restriction on the room for negotiation, because the Neuss County Council faction of the Greens were also strictly opposed to incineration. The case of the BUND was different, because at least the local representatives in Neuss appeared to be more receptive to a pragmatic solution. The BUND representatives in the Neuss mediation would have been able to accept an incineration plant based upon thermo-select waste treatment technology, or a solution similar to the Düren model. Had the Neuss County Administration proposed the Düren model, they would have probably accepted that proposal. ${ }^{8}$ So, in one way the BUND representatives were disappointed at the conduct of the Neuss County Administration, but in another, they were relieved that they had not been forced to violate the principles to which the state chapter of the BUND insisted they adhere.

Figure 6 shows the impact of the political restrictions and the Neuss County Administration's first credible commitment. The political directive for the opponents of incineration technology is given by the vertical line, $L_{G}$. This restriction permits no other solution than solution 2. The policy guideline for the supporters of waste incineration technology, represented by the horizontal line, $L_{B}$, admits only solutions 1 and 3. The area of consensus determined by these lines lies beyond all the possible solutions. If both sides had adhered strictly to the letter of predetermined policy, a negotiation procedure would not have been a rational choice, because absolute dissent would have been preprogrammed. The guidelines did not, however, represent a strict ban: as it in fact turned out, in the Neuss mediation there was indeed room for manoeuvre and this space is indicated in figure 6 by the area cir- 
Figure 6: Political Directives in the Neuss Mediation Procedure

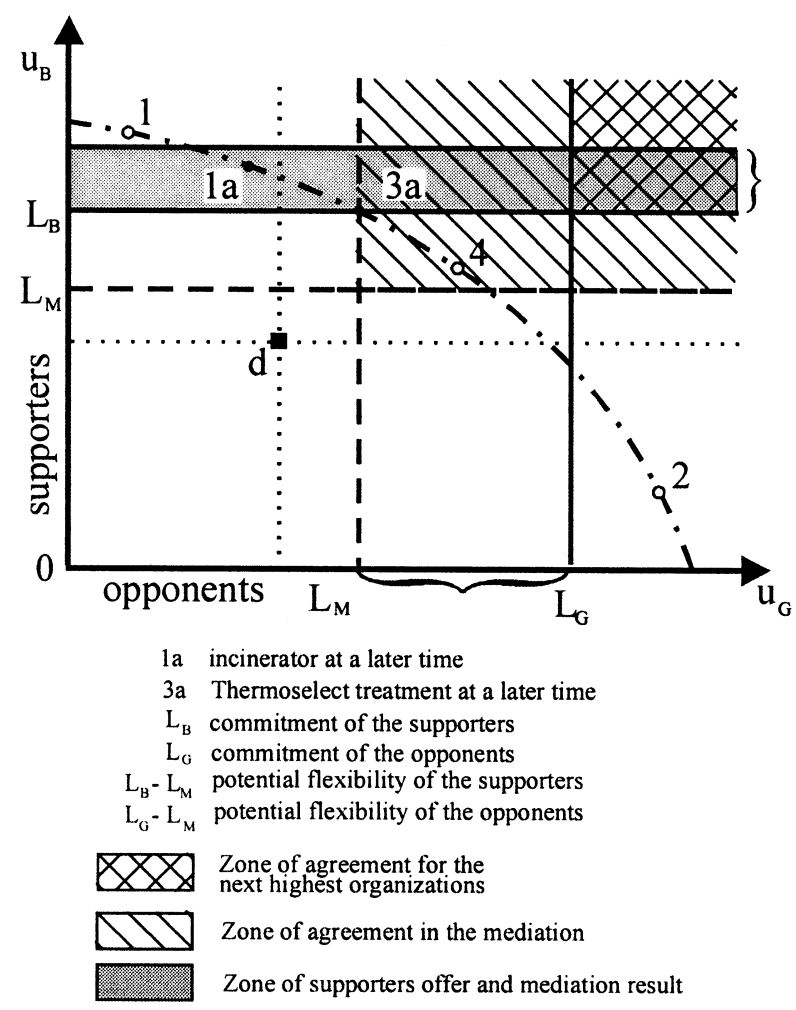

cumscribed by the vertical, $L_{M}$, and the horizontal, $L_{M}$, respectively that is, there was a potential area of compromise that included solutions 3 (thermo-select technology) and 4 (the Düren model). At the last mediation session, however, the proposal that the Neuss County Administration finally brought to the negotiation table showed that, in the end, they were not willing to go against the District Government. At this stage of the mediation, this proposal had the effect of a first credible commitment. It specified not just a single option, but rather an area of possibilities that included solutions $1 \mathrm{a}$ and $3 \mathrm{a}$ - that is, conventional incineration technology or thermo-select technology, to be implemented at a later date. This closed all of the bargaining options for the opponents of incineration technology, because the Neuss County Administration was not prepared, at this point, to commit itself definitively to a specific technology. The opponents had only the choice to either agree to the solution ' $1 \mathrm{a}$ or $3 \mathrm{a}$ ', or terminate the mediation, collapsing negotiations into dissent. Since it was not possible to exclude 
solution 1 a from the Neuss County Administration's proposal; and since 1a was considered a worse alternative than their outside option; the opponents opted for the latter.

In view of the above described exogenous influences, it should come as no surprise that the Neuss mediation ended in dissent. The room for negotiation was so drastically narrowed by the political directives of the higher-ups in the respective organizations that no room for compromise was left. The TASi functioned as an exogenous restriction that changed the set of feasible options so consequentially that the opponents of incineration had practically no chance to attain their initial goal. Against this backdrop, it is all the more astounding that, despite the adverse underlying conditions, some convergence of ideas did take place and, at least for a limited time, a compromise did seem possible. Two exogenous factors were crucially significant for this: the development of thermo-select technology and the Düren model as a frame of reference.

\section{Conclusion}

What can be learned from the application of the bargaining framework to alternative dispute resolution procedures is that researchers, who want to explain the success or failure of ADR procedures or any other kind of negotiations, should start with an analysis of the external constraints before they direct their attention to internal factors of the procedure itself. The case study has shown that external factors can, in fact, set very narrow parameters for negotiated settlements. No negotiation or discursive procedure, regardless of how well it otherwise progresses, can overcome exogenous restrictions and better outside options. There are three minimal requirements for the success of an ADR procedure. Firstly, the exogenous restrictions may not be so tight that none of the solutions that are attractive to all of the negotiation partners would be feasible. Secondly, the representatives of the conflicting parties must be allowed enough room to negotiate by their constituencies. Thirdly, there should be no structurally better outside options for the parties to the conflict.

While the literature on mediation procedures generally supports the contention that these preconditions must be met, if mediation is to be carried out successfully (for example, Zilleßen and Barbian, 1992, $29 f f$.), in most of the ADR research not much attention is given to factors external to the procedure. It is important, however, for researchers, as well as for practitioners, to take into account exogenous influences, like constraints on the feasibility of solution alternatives, the outside options of the participants and their political-strategic 
goals, as well as the limits set by their constituencies. Negotiation activities and discursive potential can only come into play whenever external factors leave some bargaining space.

If the above mentioned preconditions are met, greater flexibility of positions and a consensual outcome can be achieved, in principle, through the internal factors called for by discourse and prescriptive negotiation theory, like fair representation, face-to-face communication, better control of emotions, and more rational argumentation. However, negotiation failure should only be explained at the procedural and subjective levels after clear evidence has been offered that external constraints left sufficient room for negotiations.

\section{NOTES}

1. The positive potentials of ADR have been discussed by a number of authors, among whom are Albin (1993); Bingham (1986); Goldberg, Sander and Rogers (1992); Holznagel (1990); Hoffmann-Riem and Schmidt-Assmann (1990); Susskind and Cruikshank (1987); Weidner (1993); and Zilleßen and Barbian (1992). For more sceptical or critical views see Amy (1987); Arrow et al. (1995); Bora (1994); Coglianese (1997); Fietkau and Weidner (1995); Jansen (1997) and Holzinger (2000).

2 This term was coined by Fisher and Ury and it has been widely used; compare, for instance, Fisher, Ury and Patton (1997: 143ff.) and Susskind and Cruikshank (1987: 81f).

3 Under the heading 'outside options' will be included all possibilities for action which parties to a conflict could make use of if no bargaining took place. For reasons of economy and direct relevance, I will forego the distinction sometimes made between inside options (conflict strategies against the same partner) and outside options (shifting to new negotiation partners) (Elster 1989, $76 \mathrm{ff}$.$) .$

4 Since the quantities of residual domestic waste have declined sharply in the County of Neuss, in 1996 there no longer appeared to be a need for it to have its own residual waste incineration plant. Neuss County has since decided to enter into a cooperative agreement with a neighbouring community that already has a waste incineration plant whose capacities are not yet exhausted.

5 The preliminary talks were accompanied and recorded by a member of the WZB research team.

6 Using a two-party model is justified, insofar as the participating organizations in our real case can be reasonably divided, in principle, into two groups: the supporters and the opponents.

7 During a press conference held on 6 July 1993, following a meeting of the County Council Environment Committee intimations to this effect were made (Neuss-Grevenbroicher Zeitung, July $7,1993)$.

8 A further indicator of their willingness to compromise is the fact that after the mediation BUND representatives had prepared an amendment to the proposal to be presented at the meeting of the County Council in which the definitive decision was to be taken, wherein the BUND change foresaw the inclusion of a blueprint in the regional development plan for a thermal or a biomechanical waste treatment plant. The Greens agreed to bring this proposal to the floor.

\section{REFERENCES}

Albin, C. (1993) The Role of Fairness in Negotiation. Negotiation Journal, 9, 223-244.

Amy, D. J. (1987) The Politics of Environmental Mediation. New York: Columbia University Press.

Arrow, K. et al. (eds.) (1995) Barriers to Conflict Resolution. New York-London: Norton \& Company.

Bates, R. H. et al. (eds.) (1998) Analytical Narratives. Princeton: Princeton University Press.

Bingham, G. (1986) Resolving Environmental Dispute. A Decade of Experience. Washington: The Conservation Foundation. 
Bora, A. (1994) Grenzen der Partizipation? Risikoentscheidungen und Öffentlichkeitsbeteiligung im Recht. Zeitschrift für Rechtssoziologie, 126-152.

Coglianese, C. (1997) Assessing Consensus: The Promise and Performance of Negotiated Rulemaking. Duke Law Journal, 46, 1255-1349.

van den Daele, W. and Döbert, R. (1995) Veränderungen der äusseren Natur - Partizipative Technikfolgenabschätzung. Funkkolleg Technik, Studienbrief 4, Deutsches Institut für Fernstudienforschung an der Universität Tübingen, 4-38.

Elster, J. (1989) The Cement of Society: A Study of Social Order. Cambridge: University of Cambridge Press.

Fietkau, H.-J. et al. (1998) Umweltverhandeln. Konzepte, Praxis und Analysen alternativer Konfliktregelungsverfahren. Berlin: edition sigma.

Fietkau, JH.-J. and Weidner, H. (1995) Environmental Mediation: The Mediation Procedure on the Waste Management Plan in the District of Neuss, North Rhine-Westphalia. Schriften zu Mediationsverfahren im Umweltschutz 10, Discussion paper FS II 95-303. Berlin: Wissenschaftszentrum Berlin für Socialforschung.

Fisher R., Ury, W. and Patton, B. (1997) Getting to Yes: Negotiating an Agreement without Giving in. London: Arrow Business Books.

Goldberg, S. B., Sander, F. E., and Rogers, N. H. (eds.) (1992) Dispute Resolution. Negotiation, Mediation and Other Processes. Boston-Toronto-London: Little Brown and Company.

Habermas, J. (1984) Theory of Communicative Action, Vol. 1. London: Heinemann.

Habermas, J. (1 993) Justification and Application: Remarks on Discourse Ethics, Cambridge: Polity Press.

Hoffman-Riem, W. and Schmidt-Assmann, E. eds. (1990) Konfliktbewältigung durch Verhandllungen, Vols. I and II. Baden-Baden: Nomos.

Holzinger, K. (2001) Verhandeln statt Argumentieren oder Verhandeln durch Argumentieren? Eine empirische Analyse auf der Basis der Sprechakt theorie. Politische Vierteljahresschrift, 42, 414$44^{6}$.

Holzinger, K. (2000) Evaluating Environmental Mediation. Mediation in the Waste Management Programme of Neuss County, Germany. Results of a Participant Survey. Mediation Quarterly, 18,4 .

Holzinger, K. and Lackmann, B. (1995) Das Neusser Mediationsverfahren: Ausgangssituation, Konfliktbeteiligte, Verfahrensverlauf und Sachergebnisse. Schriften zu Mediationsverfahren im Umweltschutz 14, Discussion paper FS II 95-307. Berlin: Wissenschaftszentrum Berlin für Sozialforschung.

Holzinger, K. and Weidner, H. (1997) Das Neusser Mediationsverfahren im politischen Umfeld. Schriftenreihe zu Mediationsverfahren im Umweltschutz 17, Discussion paper FS II 97-303. Berlin: Wissenschaftszentrum Berlin für Sozialforschung.

Holznagel, B. (1990) Konfliktlösung durch Verhandlungen. Baden-Baden: Nomos.

Jansen, D. (1997) Mediationsverfahren in der Umweltpolitik. Politische Vierteljahresschrift, $3^{8,}{ }^{274}{ }^{-}$ 297.

Lax, D. A. and Sebenius, J. K. (1985) The Power of Alternatives or the Limits to Negotiation. Negotiation Journal, 1, 163-179.

Napier, G. (ed.) (1998) Environmental Conflict Resolution. London: Cameron May.

Nash, J. (1950) The Bargaining Problem. Econometrica, 18, 155-162.

Pfingsten, K. and Fietkau, H.-J. (1955) Das Neusser Mediationsverfahren aus der Sicht der Beteiligten. Ergebnisdarstellung der schriftlichen Befragung. Schriften zu Mediationsverfahren im Umweltschutz 10, Discussion paper FS II 95-302, Wissenschaftszentrum Berlin für Sozialforschung.

Putnam, R. D. (1988) Diplomacy and Domestic Politics: The Logic of Two-level Games, International Organization, 42, 427-46o.

Raiffa, H. (1982) The Art and Science of Negotiation. Cambridge, Mass.: Harvard University Press.

Rubinstein, A. (1982) Perfect Equilibrium in a Bargaining Model, Econometrica, 50; 97-109.

Scharpf, F. W. (1997) Games Real Actors Play. Actor-Centered Institutionalism in Policy Research. Boulder, Col.: Westview Press.

Schelling, T. (1960) The Strategy of Conflict. London: Oxford University Press.

Susskind, L. and Cruikshank, J. (1987) Breaking the Impasse. Consensual Approaches to Resolving Disputes. New York: Basic Books.

Weidner, H. (ed.) (1998) Alternative Dispute Resolution in Environmental Conflicts. Experiences in I2 countries. Berlin: edition sigma.

Weidner, H. (1993) Mediation as a Policy Instrument for Resolving Environmental Disputes - With Special References to Germany. Schriften zu Mediationsverfahren im Umweltschutz 3, Discussion paper FS II 93-301. Berlin: Wissenschaftszentrum Berlin für Sozialforschung. 
$96 \quad$ Katharina Holzinger

Zilleßen, H. and Barbian, T, (1992) Neue Formen der Konfliktregelung in der Umweltpolitik. Aus Politik und Zeitgeschichte, B 39-40, 14-23.

KATHARINA HOLZINGER

Max Planck Project Group on Common Goods

Law, Politics and Economics

Poppelsdorfer Allee 45

D-53 I 5 Bonn, Germany

Phone: ++49-228-91416-47

Fax: + +49-228-91416-55

Email: Holzinger@mpp-rdg.mpg.de 